\title{
Article
}

\section{Kinetics of Depolymerization of Poly(ethylene terephthalate) in a Potassium Hydroxide Solution}

Ben-Zu Wan, Chih-Yu Kao, and Wu-Hsun Cheng

Ind. Eng. Chem. Res., 2001, 40 (2), 509-514 • DOI: 10.1021/ie0005304

Downloaded from http://pubs.acs.org on November 26, 2008

\section{More About This Article}

Additional resources and features associated with this article are available within the HTML version:

- $\quad$ Supporting Information

- $\quad$ Links to the 5 articles that cite this article, as of the time of this article download

- Access to high resolution figures

- $\quad$ Links to articles and content related to this article

- $\quad$ Copyright permission to reproduce figures and/or text from this article

View the Full Text HTML 


\title{
Kinetics of Depolymerization of Poly(ethylene terephthalate) in a Potassium Hydroxide Solution
}

\author{
Ben-Zu Wan, ${ }^{*, \dagger}$ Chih-Yu Kao, ${ }^{\dagger}$ and Wu-Hsun Cheng ${ }^{\ddagger}$ \\ Department of Chemical Enginering, National Taiwan University, Taipe, Taiwan, and Department of \\ Chemical Engineering, Chang Gung University, Kweishan, Taoyuan, Taiwan
}

\begin{abstract}
The depolymerization of poly(ethylene terephthalate) (PET) flakes in a potassium hydroxide solution was carried out in a stirred batch reactor at 120,140 , and $160{ }^{\circ} \mathrm{C}$, below its melting point and under pressures of about 1.7, 2.9, and 4.6 atm, respectively. After the reactions, the residual solids almost remained in flake shape and their molecular weights were close to that of PET before the reaction. The products composed of ethylene glycol and terephthalic potassium salt were in the liquid phase. They were separated by acidification (to obtain solid terephthalic acid) and filtration processes and subsequently were analyzed quantitatively by potentiometric titration, el ementary analysis, and gas chromatography. The results of kinetic analysis showed that the depolymerization reaction rate was first order to potassium hydroxide and first order to the PET concentration. This indicates that the ester linkages on the surface of the solid PET flakes sequentially reacted with potassium hydroxide in the solution to produce ethylene glycol and terephthalic potassium salt. A mechanism for the major reaction occurring on the polymer chain end section on the solid PET surface was proposed in this research. The dependence of the rate constant on the reaction temperature was correlated by the Arrhenius plot, which shows an activation energy of $69 \mathrm{~kJ} / \mathrm{mol}$ and an Arrhenius constant of $419 \mathrm{~L} / \mathrm{min}^{\mathrm{n}} / \mathrm{cm}^{2}$.
\end{abstract}

\section{Introduction}

Poly(ethylene terephthalate) (PET) is a thermoplastic polyester, which is largely consumed in packaging bottles. The interest in PET recycling is continuously growing because of ecological and economic considerations. $^{1,2}$ Among the methods of polymer recycling, chemical recycling, which applied in the case of postconsumer condensation polymers, draws great interest. The chemical recycling of postconsumer PET has recently been paid much attention, and a review paper concerning the subject has been published. ${ }^{3}$ The processes for chemical recycling of waste PET are mainly divided into (i) methanolysis, (ii) glycolysis, and (iii) hydrolysis. The application of these recycling processes is dependent on the end use of recovered products. A growing interest is thus focused on the process development of hydrolysis of PET in which terephthalic acid (TPA) and ethylene glycol (EG) are recovered and can be directly used in the synthesis of virgin PET. ${ }^{4-6}$

The hydrolytic depolymerization of PET was usually conducted at temperatures above the melting point of the resins to obtain reaction rates applicable in the industrial process. ${ }^{7-9}$ Zinc acetate was used to catalyze the reactions; however, the catalytic effect was still limited. ${ }^{8}$ Traditionally, strong acids or bases are effec-

* Corresponding author. E-mail: benzuwan@ccms.ntu.edu.tw. Fax: (+886-2) 23623040.

+ National Taiwan University.

₹ Chang Gung University. tive catalysts for the hydrolysis of esters. Sulfuric acid had been used to catalyze the hydrolysis of PET at temperatures below $150^{\circ} \mathrm{C},{ }^{10,11}$ but the corrosion of the equipment and the separation of ethylene glycol from the waste acid were critical problems in the process. There have been patented several processes of hydrolyzing PET in aqueous solutions of alkal ine hydroxides. ${ }^{12,13}$ In the processes, the depolymerization reactions were carried out under moderate conditions, and ethylene glycol and terephthalic salts (instead of TPA) were recovered. Moreover, the processes of alkaline hydrolysis of PET in the organic solvents have been reported. ${ }^{14-17}$ Nevertheless, al though al kal ine hydroxides were found to possess high activity for the depolymerization of PET, very few reaction kinetics studies have been conducted. Zeronian and co-workers extensively investigated the depolymerization reactions that occurred on the surface of PET with sodium hydroxide; ${ }^{18,19}$ however, their experiments were performed at ambient temperature, and the reaction rates were rather low. The result of their studies did not reach the requirements for the industrial depolymerizing process. Therefore, in the past there were no detailed data available about product characterization and reaction kinetics, which were necessary for devel oping the process of depolymerization of PET in alkaline solutions.

In our previous work, ${ }^{20}$ the depolymerization of PET with alkaline hydroxides in the solid state was investigated by the techniques of thermal analysis. The characterization of the products and the kinetic analysis 
of isoconversion were performed. It was concluded in this study that potassium hydroxide possessed better activity than sodium hydroxide for the depolymerization of PET. Therefore, the detailed reaction kinetics of the PET depolymerization in a potassium hydroxide solution was investigated using a pressurized autoclave in the present study. The kinetic data under the reaction temperatures below the PET melting point were obtained. F urthermore, the reaction kinetic models were discriminated, and the possible reaction mechanism was proposed.

\section{Experimental Section}

The commercially recycled PET flakes (thickness = $0.39 \mathrm{~mm}$ and density $=1.18 \mathrm{~g} / \mathrm{cm}^{3}$ ) from beverage bottles were used in the experiments of depolymerization in a potassium hydroxide solution. The intrinsic viscosity (IV) of PET was measured in a $6: 4(\mathrm{w} / \mathrm{w})$ phenol/1,1,2,2-tetrachloroethane solution at $30^{\circ} \mathrm{C}$. The IV value of $0.72 \mathrm{dL} / \mathrm{g}$, corresponding to the average molecular weight (M) of 22400 , was cal culated from the equation $\mathrm{M}=3.61 \times 10^{4} \mathrm{IV} \mathrm{V}^{1.46 .21}$ The experiments of PET depolymerization were carried out in a Parr 4560 minireactor equipped with a bomb of $300 \mathrm{~mL}$ and a motor for stirring. The reactants of PET flakes, potassium hydroxide, and water were charged into the reactor at room temperature and then heated directly to the temperatures specified for conducting hydrolytic reactions. After the required time interval for the depolymerization reaction was reached, the vessel was quickly removed from the heating mantle and immersed in an ice bath. The temperature of the vessel was quenched to ambient conditions so as to interrupt the progress of the PET hydrolysis. The residual flakes and the alkaline solution were removed from the bomb and were separated by filtration. The flakes were further washed, dried, and weighed. The melting thermogram of the residual PET was investigated by a differential scanning calorimeter (Du Pont 910 DSC) at a heating rate of 10 ${ }^{\circ} \mathrm{C} / \mathrm{min}$. The IV and $\mathrm{M}$ of the residual PET were determined.

After the depolymerization reactions, the products of terephthalic potassium salt and ethylene glycol, besides the unreacted potassium hydroxide, were dissolved in the solution liquid phase. The liquids were separated from the solution by filtration. Sulfuric acid was added into the filtrate to neutralize the potassium hydroxide. The solid TPA was precipitated and was separated again by filtration. The solid product was further washed by deionized water, dried at $80^{\circ} \mathrm{C}$, and ground until a fine powder was obtained. The remaining liquid, mainly composed of water and ethylene glycol, was directly used for analysis.

The carboxylic acid concentration in the solid products was determined by potential titration. ${ }^{7} \mathrm{~A}$ total of $25 \mathrm{~mL}$ of DMSO was used as the solvent, in which $0.1-0.2 \mathrm{~g}$ of solid product was dissolved. The solution was titrated with a $0.1 \mathrm{~N}$ potassium hydroxide/ethanol solution at room temperature. The potential of the sol ution versus the amount of the titrant added was recorded, and the plot was then used to determine the end point of titration. The experimental error of the titration was about $1 \%$. Moreover, the elemental composition for carbon and hydrogen was measured using an elemental analyzer (Perkin-Elmer 2400).

The concentrations of the organic products in the remaining liquid were quantitatively analyzed by gas

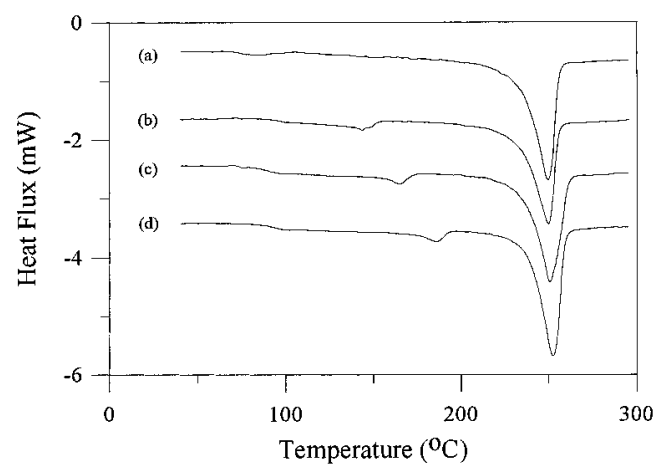

Figure 1. DSC thermograms for the residual PET flakes after the alkaline hydrolysis of PET (PET:KOH = 1:4) for $30 \mathrm{~min}$ at different temperatures: (a) original flakes; (b) $120^{\circ} \mathrm{C}$; (c) $140{ }^{\circ} \mathrm{C}$; (d) $160^{\circ} \mathrm{C}$

chromatography. 1-Propanol was used as an internal standard. The mixed solution was injected into a gas chromatograph and separated by a $2 \mathrm{~m}$ stainless steel column packed with DEGS 60/80 chromosorb WAW DMCS. The components were carried by a nitrogen flow and detected by a flame ionization detector.

\section{Results and Discussion}

PET Depolymerization in Potassium Hydroxide Solutions. For $15 \mathrm{~g}$ of PET flakes depolymerized in 90 $\mathrm{mL}$ of a potassium hydroxide solution (mole ratio of PET repeating units to $\mathrm{KOH}=1: 4$ ) for $30 \mathrm{~min}$ at 120,140 , or $160{ }^{\circ} \mathrm{C}$, it was found that the amount of PET flakes decomposed increased with the reaction temperatures. Especially for the case at $160{ }^{\circ} \mathrm{C}$, most of the charged flakes had been completely depolymerized and only a few small pieces remained. After removal of the remaining flakes by filtration and carrying out of the processes of neutralization of the solution liquid phase and filtration again, the liquid (filtrate) obtained was analyzed by gas chromatography for organic products. Only ethylene glycol was found. The solid products were analyzed by elemental analysis. All of the element compositions were found to be the same as those of TPA within experimental errors $(0.1 \%$ for hydrogen and $0.2 \%$ for carbon); moreover, the titration for these solid products showed that the acid concentrations of solid products were close to the value of TPA, $12.1 \mathrm{mmol} / \mathrm{g}$ of TPA. These results indicate that TPA was the solid product obtained after neutralization.

The DSC thermograms for the melting endotherms of the fresh PET flakes and the remaining flakes, after the above experiments, are presented in Figure 1. For the cases of the remaining flakes, large endothermic bands at about $250{ }^{\circ} \mathrm{C}$ and a few small endothermic bands below $200{ }^{\circ} \mathrm{C}$ can be observed. The large bands were similar to that of PET melting of the fresh flakes except that the endothermic bands of the remaining PET were narrower and slightly shifted toward the region of high temperatures. The results suggest that most of the remaining flakes still maintained their original PET structure. However, a few small endothermic bands below $200{ }^{\circ} \mathrm{C}$ should correspond to the oligomers with low molecular weights produced on the surface of PET flakes during depolymerization reactions. Table 1 lists the results of IV and M for the remaining PET flakes after the reactions. The molecular weight of unreacted flakes was large and slightly decreased with an increase of the reaction temperatures; however, 
Table 1. Intrinsic Viscosity (IV) and Average Molecular Weight (M) of the Residual PET Flakes after Alkaline Hydrolysis ${ }^{\mathrm{a}}$

\begin{tabular}{ccc}
\hline PET & IV $(\mathrm{dL} / \mathrm{g})$ & $\mathrm{M}^{\mathrm{b}}$ \\
\hline unreacted & 0.72 & 22400 \\
A $\left(120^{\circ} \mathrm{C}\right)$ & 0.72 & 22400 \\
$\mathrm{~B}\left(140^{\circ} \mathrm{C}\right)$ & 0.70 & 21500 \\
$\mathrm{C}\left(160^{\circ} \mathrm{C}\right)$ & 0.67 & 20100
\end{tabular}

a In each batch of the feed, the weight of PET flakes was $15 \mathrm{~g}$; mole ratio of $\mathrm{PET}: \mathrm{KOH}=1: 4$; reaction time $=30 \mathrm{~min}$; temperature $=120,140$, or $160{ }^{\circ} \mathrm{C}$; total volume $=90 \mathrm{~mL}$. ${ }^{\mathrm{b}} \mathrm{M}=3.61 \times$ $10^{4} \mathrm{IV}^{1.46} \cdot 21$

Table 2. Temperature Effect on PET Conversions and TPA Yields for Depolymerization of PET in a Potassium Hydroxide Solution ${ }^{\mathrm{a}}$

\begin{tabular}{ccc}
\hline temp $\left({ }^{\circ} \mathrm{C}\right)$ & PET conv $(\%)$ & TPA yiel $^{\mathrm{b}}(\%)$ \\
\hline 120 & 17.8 & 17.7 \\
140 & 47.8 & 47.4 \\
160 & 92.2 & 90.9
\end{tabular}

a The weight of PET flakes was $15 \mathrm{~g}$; mole ratio of PET:KOH = 1:4; reaction time $=30 \mathrm{~min}$; total volume $=90 \mathrm{~mL}$. ${ }^{\mathrm{b}}$ TPA yield $=$ (no. of moles of TPA produced)/(no. of moles of PET charged).

Table 3. Effect of the Molar Ratio of PET to Potassium Hydroxide on the PET Conversions and TPA Yields of the PET Depolymerizatona

\begin{tabular}{lccc}
\hline hydroxide & molar ratio $^{b}$ & PET conv $(\%)$ & TPA yield (\%) \\
\hline $\mathrm{KOH}$ & $1: 1$ & 3.6 & 3.7 \\
$\mathrm{KOH}$ & $1: 2$ & 8.6 & 9.1 \\
$\mathrm{KOH}$ & $1: 4$ & 17.8 & 17.7
\end{tabular}

a Temperature $=120^{\circ} \mathrm{C}$; reaction time $=30 \mathrm{~min}$; total volume $=90 \mathrm{~mL} ; 15 \mathrm{~g}$ of fresh PET flakes charged. ${ }^{\mathrm{b}}$ PET repeating units to potassium hydroxide.

for the case of the highest temperature (i.e., $160^{\circ} \mathrm{C}$ ), $\mathrm{M}$ of the remaining PET was still higher than 20000 . Therefore, the bulk phase of the remaining flakes after the reactions was cl ose to the fresh PET of long chains. This suggests that the depolymerization of PET in potassium hydroxide solutions occurred on the external surface of the PET flakes, and the flakes were lamellarly depolymerized.

Because the remaining flakes after the depolymerization reaction in a potassium hydroxide sol ution were similar to the fresh PET, the conversion of PET can be calculated from the weight difference between the fresh PET flakes before the reactions and the remaining flakes after the reactions. The yields of TPA can be calculated from the moles of TPA solids collected after the reaction and the neutralization processes, divided by the moles of the PET repeating units charged before the reaction. Table 2 lists the conversions of PET and the yields of TPA after the depolymerization in a potassium hydroxide solution for $30 \mathrm{~min}$ at different temperatures. Table 3 lists those at $120^{\circ} \mathrm{C}$ for $30 \mathrm{~min}$ at different potassium hydroxide concentrations. It can be observed that the conversion of PET apparently increased with the reaction temperature and with the concentration of potassium hydroxide. Theyields of TPA were approximately equal to the conversions of PET. The results indicate that the solid PET depolymerized in the potassium hydroxide solutions at different concentrations and at different temperatures produced al most only terephthalic salt and ethylene glycol in the solution. Although the products of oligomers were observed on the remaining PET solid flakes from DSC studies, they did not exist in the solution during reactions.

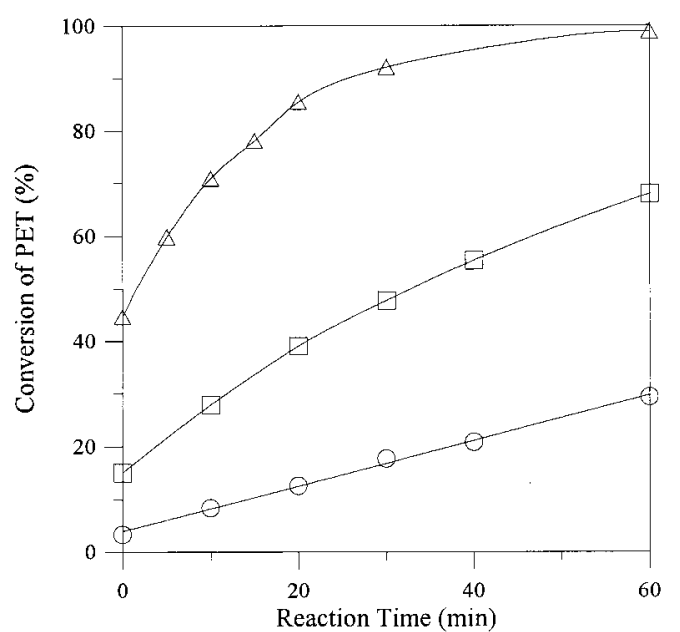

Figure 2. PET conversion of alkaline hydrolysis (PET:KOH $=$ $1: 4)$ as a function of reaction time at $(O) 120,(\square) 140$, or $(\triangle) 160$ ${ }^{\circ} \mathrm{C}$ and under pressures at $1.7,2.9$, and 4.6 atm, respectively.

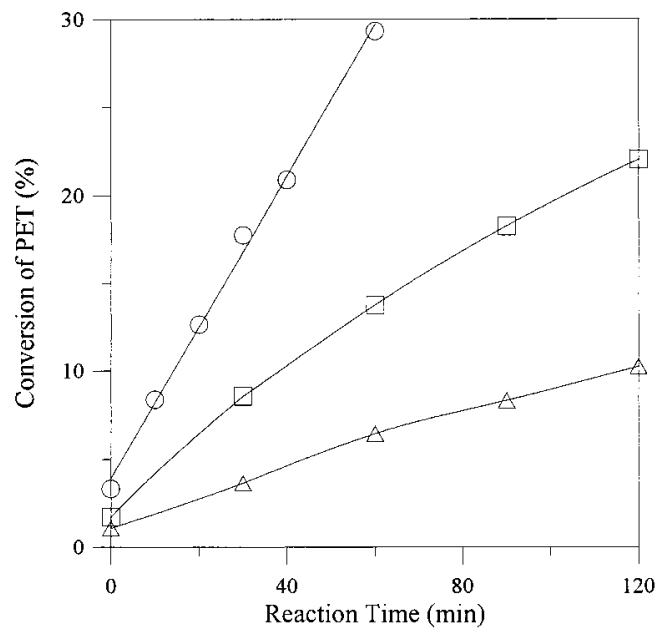

Figure 3. PET conversion of alkaline hydrolysis at $120^{\circ} \mathrm{C}$ as a function of reaction time with charge ratios PET:KOH of $(O) 1: 4$, ( $\square$ ) $1: 2$, or $(\triangle) 1: 1$.

Kinetics Data. The PET conversions as a function of reaction time at different reaction temperatures (PET: $\mathrm{KOH}=1: 4$ ) are depicted in Figure 2 . In the case of 160 ${ }^{\circ} \mathrm{C}$, the initial conversion reached $45 \%$, which was caused by the reaction extent accumulated during the period of heating from room temperature to the set reaction temperature. In the other cases with low reaction temperatures, the initial conversions were bel ow 20\%. Figure 3 shows the increase of the PET conversion with reaction time in the variation of the charge ratio (at $120^{\circ} \mathrm{C}$ ). The initial conversions were smaller than $5 \%$. Increasing with the reaction time, the difference of PET conversions in the three cases increased. The reaction rate, the slope of the curve, was found to be roughly proportional to the concentration of potassium hydroxide. Furthermore, the effect of the PET concentration on the PET conversion was examined at $120^{\circ} \mathrm{C}$, while in the experiments the concentrations of $\mathrm{KOH}$ were maintained constant $(1.73 \mathrm{~mol} / \mathrm{L})$ and 5 , 10,15 , and $25 \mathrm{~g}$ of PET were used in $90 \mathrm{~mL}$ of solution at the initial reaction time. It was found that nearly the same PET conversions (8\%) were obtained for different charges of PET for a $0.5 \mathrm{~h}$ initial reaction period. The results clearly indicate that the initial reaction rates are exactly proportional to the concentrations of PET; therefore, the reaction of the PET conversion in the 
potassium hydroxide solution is first order to the PET concentration.

(a) Kinetic Model. The experimental results showed that the conversions of PET were consistent with the yields of monomeric products. The reaction rate $\left(-r_{A}\right.$; in $\mathrm{mol} / \mathrm{L} / \mathrm{min}$ ) of alkaline hydrolysis of PET (or the production rate either of ethylene glycol or of terephthalic potassium salt) can thus be defined by the mole consumption rate of the PET repeating unit per unit reaction volume. Because the product of TPA produced in the alkaline hydrolysis of PET was dissolved in the solution and became of its salt form, the terephthalic salt would be inactive to a nucleophilic substitution for the esterification (the reverse reaction for the alkal ine hydrolysis). Therefore, the reaction of PET hydrolysis in a potassium hydroxide solution is an irreversible reaction. The reaction rate equation can be simply expressed as the following power form:

$$
-\mathrm{r}_{\mathrm{A}}=\left(\mathrm{N}_{\mathrm{Ai}} N\right)\left(\mathrm{dX}_{\mathrm{A}} / \mathrm{dt}\right)=\mathrm{kC}_{\mathrm{A}} \mathrm{C}_{\mathrm{B}}^{\mathrm{b}}
$$

where $\mathrm{N}_{\mathrm{Ai}}$ represents moles of PET repeating units charged in the solution, $V(L)$ represents the total reaction volume, $\mathrm{X}_{\mathrm{A}}$ represents the PET conversion, $\mathrm{t}$ represents the reaction time, $C_{A}$ represents the concentration of $P E T, C_{B}(\mathrm{~mol} / \mathrm{L})$ represents the concentration of potassium hydroxide, $\mathrm{k}$ is the rate constant, and $\mathrm{b}$ is the reaction order with respect to potassium hydroxide. Note that, because only the surface of the PET solid is available for the reaction, $C_{A}$ is defined as the PET surface area $\left(\mathrm{cm}^{2}\right)$ divided by the total reaction volume (L). Moreover, because the PET solid used in this research is in flake shape and the thickness of the flake is $0.039 \mathrm{~cm}$, a constant surface area of the PET solid and constant $C_{A}$ are assumed during the course of the reaction. If a constant volume for the reactions is assumed, the balance equation in terms of the PET conversion $\left(\mathrm{X}_{\mathrm{A}}\right)$ can be expressed as

$$
\mathrm{dX}_{\mathrm{A}} / \mathrm{dt}=\mathrm{kN}_{\mathrm{AS}} \mathrm{V}^{-\mathrm{b}} \mathrm{N}_{\mathrm{Ai}}{ }^{\mathrm{b}-1}\left(\mathrm{M}-2 \mathrm{X}_{\mathrm{A}}\right)^{\mathrm{b}}
$$

where $\mathrm{N}_{\mathrm{As}}\left(\mathrm{cm}^{2}\right)$ represents the surface area of the PET flakes, which can be calculated from the initial weight (g) of PET divided by $1.18 \mathrm{~g} / \mathrm{cm}^{3}$ of PET density and by the $0.039 \mathrm{~cm}$ flake thickness used in this study and $\mathrm{N}_{\mathrm{Bi}}$ represents moles of $\mathrm{KOH}$ charged in the solution. $\mathrm{M}$ is the charge ratio, which is defined by $M=N_{B i} / N_{A i}$.

In this study, we proposed two different kinetic models in regard to rate order $b=1$ and 2 and derived their integration forms for different values of the charge ratio (M). The equations for the relationship between the PET conversion and reaction time are as follows:

$$
2 \mathrm{kN}_{\mathrm{As}} \mathrm{V}^{-1} \mathrm{t}=\ln \left[\left(\mathrm{M}-2 \mathrm{X}_{\mathrm{A} 0}\right) /\left(\mathrm{M}-2 \mathrm{X}_{\mathrm{A}}\right)\right] \quad \text { for } \mathrm{b}=1
$$

$$
\begin{array}{r}
2 \mathrm{kN}_{\mathrm{As}} \mathrm{V}^{-2} \mathrm{~N}_{\mathrm{Ai}} \mathrm{t}=1 /\left(\mathrm{M}-2 \mathrm{X}_{\mathrm{A}}\right)-1 /\left(\mathrm{M}-2 \mathrm{X}_{\mathrm{AO}}\right) \\
\text { for } \mathrm{b}=2
\end{array}
$$

$\mathrm{X}_{\mathrm{A} 0}$ represents the $\mathrm{PET}$ conversion at zero reaction time. These kinetic models were examined by fitting them to the experimental data listed in Table 4, where the concentrations of PET $\left(\mathrm{N}_{\mathrm{As}} \mathrm{V}^{-1}\right)$ and the total reaction volume $(\mathrm{V})$ were treated as constants and three different charge ratios (M) were used at $120^{\circ} \mathrm{C}$ reaction temper-

\begin{tabular}{|c|c|c|c|c|c|}
\hline \multicolumn{2}{|c|}{$M=1$} & \multicolumn{2}{|c|}{$M=2$} & \multicolumn{2}{|c|}{$M=4$} \\
\hline$t(\min )$ & $X_{A}$ & $t(\min )$ & $X_{A}$ & $\mathrm{t}(\mathrm{min})$ & $X_{A}$ \\
\hline 0 & 0.011 & 0 & 0.017 & 0 & 0.033 \\
\hline 30 & 0.037 & 30 & 0.086 & 10 & 0.084 \\
\hline 60 & 0.065 & 60 & 0.138 & 20 & 0.126 \\
\hline 90 & 0.083 & 90 & 0.183 & 30 & 0.178 \\
\hline 120 & 0.102 & 120 & 0.221 & 40 & 0.209 \\
\hline
\end{tabular}
ature. In the case where the models fit the reaction tendency well, the relation of reaction time versus In-
Table 4. Reaction Kinetic Data at $120^{\circ} \mathrm{C}$ Used in Modelinga

a $\mathrm{M}=$ charge ratio. $\mathrm{X}_{\mathrm{A}}=\mathrm{PET}$ conversion.

$\left[\left(M-2 X_{A 0}\right) /\left(M-2 X_{A}\right)\right]$ from eq 3 and the relation of reaction time versus $1 /\left(M-2 X_{A}\right)-1 /\left(M-2 X_{A 0}\right)$ from eq 4 should be linear and the slopes should be constants (independent of the charge ratios, M). From the fitting results, it is found that both models provide a good linear relationship; the linear correlation factors $\left(R^{2}\right)$ of the fittings from eq 3 are above 0.989 for different charge ratios, and those from eq 4 are above 0.996 . Nevertheless, according to eq 4, the slopes from the fittings with different charge ratios were in a wide range. The average value with a standard deviation of $(1.2 \pm 0.7) \times 10^{-3}$ was calculated. According to eq 3 , the slopes from different charge ratios were in a much narrower range. The average value with a standard deviation of $(2.1 \pm 0.3) \times 10^{-3}$ was calculated. Apparently, eq 3, in which the reaction rate is first order to the PET concentration and first order to the $\mathrm{KOH}$ concentration, is the better model to describe the reaction kinetics of the solid PET depolymerization in the potassium hydroxide solution. The slight difference in the value of $2 \mathrm{kN}_{\mathrm{As}} \mathrm{V}^{-1}$ (the slope) from this model when the charge ratio was changed might be possibly for two reasons. One was, because the ideal solutions were assumed in this research, the actual reaction volumes were not correctly estimated. The other was, because the actual surface area of the PET flakes per reaction volume was not easily controlled to be equal during the reaction, the assumption of constant $\mathrm{N}_{\mathrm{As}} \mathrm{V}^{-1}$ may contribute some errors in the model analysis.

The fitting results of the model in eq 3 to the experimental data at different temperatures are shown in Figure 4 . In the case of $140^{\circ} \mathrm{C}$, the fitting was pretty good; however, in the case of $160{ }^{\circ} \mathrm{C}$, the fitting for the low conversions was good, but the model did not fit to the data with conversions higher than $90 \%$. Estimated from the slopes in the plot, the rate constants are listed in Table 5. According to the relationship of the rate constant with the reaction temperature, the Arrhenius plot is shown in Figure 5. The activation energy for the alkaline hydrolysis of PET cal culated from the slope was $69 \mathrm{~kJ} / \mathrm{mol}$, and the Arrhenius constant calculated from the intercept was $419 \mathrm{~L} / \mathrm{min} / \mathrm{cm}^{2}$.

(b) Reaction Mechanism. F or the depolymerization of PET in a potassium hydroxide solution, 1 mol of PET repeating unit should react with 2 mol of alkaline hydroxides to produce $1 \mathrm{~mol}$ each of terephthalic salt and ethylene glycol. However, the result of kinetic analysis showed that the reaction rate was first order to PET and first order (not second order) to the potassium hydroxide concentration. This suggests that the molecules of potassium hydroxi de react one by one with the ester linkage on the surface of the PET flakes to produce ethylene glycol or terephthalic potassium salt rather than react with two ester linkages of PET repeating units at the same time; moreover, the first reaction step should be the reaction rate-limiting step. 


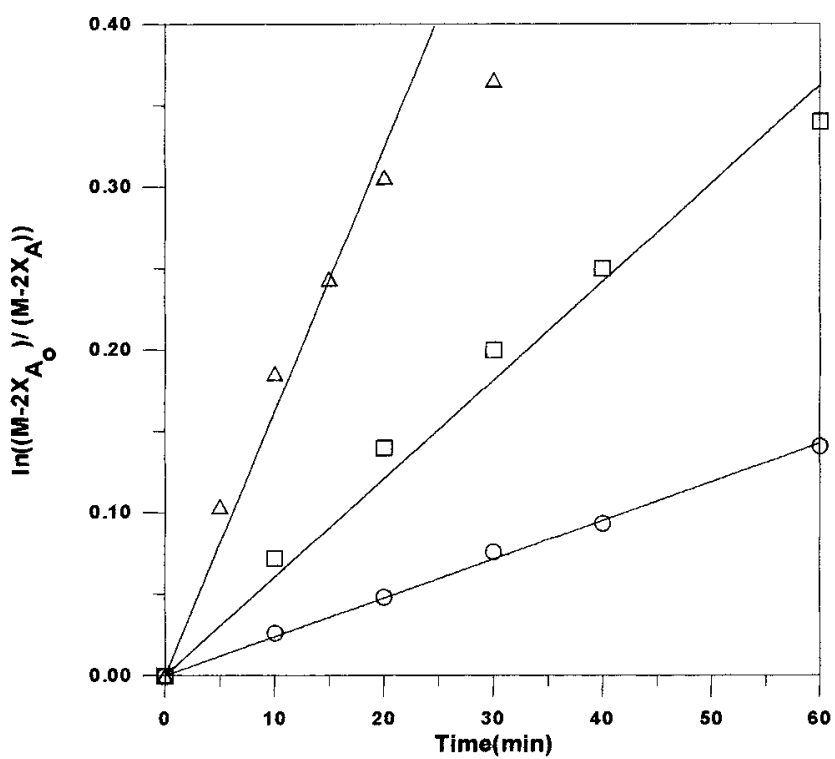

Figure 4. Fitting of kinetic data by the model of eq 3 for the alkaline hydrolysis of PET (PET:KOH = 1:4) at (O) 120, ( $\square$ ) 140, or $(\triangle) 160{ }^{\circ} \mathrm{C}$ and under pressures at $1.7,2.9$, and 4.6 atm, respectively.

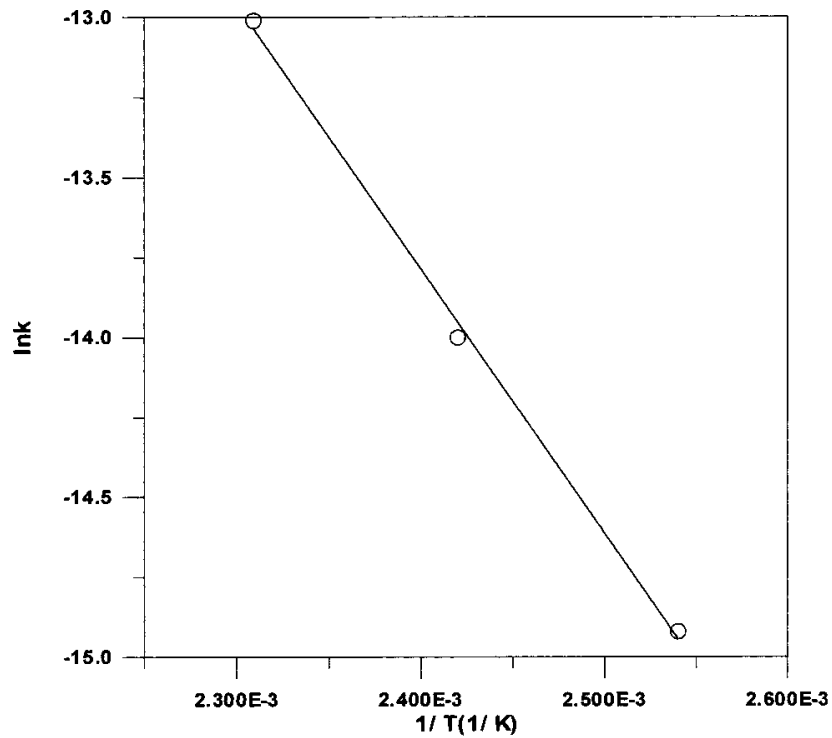

Figure 5. Arrhenius plot for the alkaline hydrolysis of PET (PET: $\mathrm{KOH}=1: 4)$

Table 5. Reaction Rate Constants of PET Depolymerization in a Potassium Hydroxide Solution at Different Temperatures

\begin{tabular}{cc}
\hline temp $\left({ }^{\circ} \mathrm{C}\right)$ & rate constant $\left[\times 10^{-7}\left(\mathrm{~L} / \mathrm{min} / \mathrm{cm}^{2}\right)\right]$ \\
\hline 120 & 3.32 \\
140 & 8.31 \\
160 & 22.4
\end{tabular}

Because from DSC studies the ol igomers were found on the solid PET surface after the reaction, the random scissions of ester linkage on the PET surface may have occurred in the reaction. However, the reaction occurring on the polymer chain end section should be the major reaction. Otherwise, each mol ecule of potassium hydroxide that reacts with the ester linkage on the solid surface of PET would not possibly only produce either a ethylene glycol or a terephthalic potassium salt in the solution. The reaction rate defined in this research is not possibly first order to the potassium hydroxide concentration. The reaction rate in the potassium hydroxide solution is close to first order with respect to the potassium hydroxide concentration. Therefore, the major reaction steps of alkaline hydrolysis of PET can be expressed as follows: Equation 5 is the rate limiting

$$
\begin{gathered}
\sim \mathrm{C}_{6} \mathrm{H}_{4}-\mathrm{CO}-\mathrm{OC}_{2} \mathrm{H}_{4} \mathrm{O}-\mathrm{CO}-\mathrm{C}_{6} \mathrm{H}_{4}-\mathrm{CO}-\mathrm{OC}_{2} \mathrm{H}_{4} \mathrm{OH}+ \\
\mathrm{KOH} \rightarrow \sim \mathrm{C}_{6} \mathrm{H}_{4}-\mathrm{CO}-\mathrm{OC}_{2} \mathrm{H}_{4} \mathrm{O}-\mathrm{OC}-\mathrm{C}_{6} \mathrm{H}_{4}-\mathrm{COOK}+ \\
\mathrm{HOC}_{2} \mathrm{H}_{4} \mathrm{OH} \\
\quad(5) \\
\sim \mathrm{C}_{6} \mathrm{H}_{4}-\mathrm{CO}-\mathrm{OC}_{2} \mathrm{H}_{4} \mathrm{O}-\mathrm{OC}-\mathrm{C}_{6} \mathrm{H}_{4}-\mathrm{COOK}+ \\
\mathrm{KOH} \rightarrow \sim \mathrm{C}_{6} \mathrm{H}_{4}-\mathrm{CO}-\mathrm{OC}_{2} \mathrm{H}_{4} \mathrm{OH}+\mathrm{KOOC}-\mathrm{C}_{6} \mathrm{H}_{4}-
\end{gathered}
$$

step. This reaction mechanism is different from that for the hydrolysis of melt PET in neutral water, where a random scission model fully contributes to the breaking of ester linkages and subsequently producestheproducts. ${ }^{7-9}$ Nevertheless, the PET depolymerization reaction rate in the neutral water solution is much slower than that in the potassium hydroxide solution. Therefore, to enhance the reaction rate, reaction temperatures higher than $230{ }^{\circ} \mathrm{C}$ are required for reactions in the neutral water solution, in contrast to those at about $150{ }^{\circ} \mathrm{C}$ for the reactions in the potassium hydroxide solutions.

\section{Conclusions}

The hydrolytic depolymerization of PET in the agitated potassium hydroxide solution was investigated. It was found that the depolymerization reaction rate in a potassium hydroxide solution is much faster than that in a neutral water solution. The correl ation between the yield of product and the conversion of PET showed that the major alkaline hydrolysis of PET linkages was through a mechanism of chain-end scission. The result of kinetic analysis showed that the reaction rate was first order each to the concentration of potassium hydroxide and to the concentration of PET solids, respectively. This suggests that the ester linkages in PET were hydrolyzed sequentially. The activation energy for the depolymerization of solid PET in a potassium hydroxide solution was $69 \mathrm{~kJ} / \mathrm{mol}$, and the Arrhe nius constant was $419 \mathrm{~L} / \mathrm{min} / \mathrm{cm}^{2}$.

\section{Acknowledgment}

The financial support for this work provided by the National Science Council of R.O.C. is gratefully acknowledged. The authors also thank Mr. Guo-Feng Yang of National Taiwan University for doing some of the experimental work in this research.

\section{Nomenclature}

$\mathrm{b}=$ reaction rate order to the potassium hydroxide concentration

$\mathrm{C}_{\mathrm{A}}=$ concentration of PET, surface area of solid PET divided by the reaction volume, $\mathrm{cm}^{2} / \mathrm{L}$

$\mathrm{C}_{\mathrm{B}}=$ concentration of potassium hydroxide, $\mathrm{mol} / \mathrm{L}$

$\mathrm{k}=$ reaction rate constant, $\mathrm{L} / \mathrm{cm}^{2} / \mathrm{min}$

$\mathrm{M}=\mathrm{N}_{\mathrm{Bi}} / \mathrm{N}_{\mathrm{Ai}}$

$\mathrm{N}_{\mathrm{Ai}}=$ moles of PET repeating units charged in the reactor before the reaction

$\mathrm{N}_{\mathrm{Bi}}=$ moles of $\mathrm{KOH}$ charged in the reactor before the reaction

$\mathrm{N}_{\mathrm{As}}=$ surface area of the PET flakes, $\mathrm{cm}^{2}$

$-r_{A}=$ reaction rate of the PET depolymerization, moles of PET repeating units depolymerized per unit reaction volume per unit time, $\mathrm{mol} / \mathrm{L} / \mathrm{min}$ 
$\mathrm{t}=$ reaction time, $\min$

$\mathrm{V}=$ reaction volume, $\mathrm{L}$

$\mathrm{X}_{\mathrm{A}}=\mathrm{PET}$ conversion, disappearing weight of PET divided

by the initial weight of PET

$\mathrm{X}_{\mathrm{A} 0}=\mathrm{PET}$ conversion when $\mathrm{t}=0$

\section{Literature Cited}

(1) Nir, M. M.; Miltz, J .; Ram, A. U pdate on Plastics and the Environment. Progress and Trends. Plast. Eng. 1993, 49, 75.

(2) Mayers, J . PET Bottle Growth is Outpacing Resins Supply. Mod. Plast. Int. 1994, Dec, 46.

(3) Paszun, D.; Spychaj, T. Chemical Recycling of Poly(ethylene terephthalate). Ind. Eng. Chem. Res. 1997, 36, 1373.

(4) Cudmore, W. J . G. Polyethylene Terephthalate Saponification. U.S. Patent 4,578,502, 1986.

(5) Doerr, M. L. Process for Minimizing Formation of Low Molecular Weight Oligomers during Hydrolytic Depolymerization of Condensation Polymers. U.S. Patent 4,578,510, 1986.

(6) Rosen, B. I. Preparation of Purified Terephthalic Acid from Waste Polyethylene Terephthalate. U.S. Patent 5,095,145, 1992.

(7) Campanelli, J . R.; Kamal, M. R.; Cooper, D. G. A Kinetic Study of the Hydrolytic Degradation of Polyethylene Terephthalate at High Temperatures. J. Appl. Polym. Sci. 1993, 48, 443.

(8) Campanelli, J . R.; Cooper, D. G.; Kamal, M. R. Catalyzed Hydrolysis of Polyethylene Terephthalate Melts. J . Appl. Polym. Sci. 1994, 53, 985.

(9) Kao, C.-Y.; Wan, B.-Z.; Cheng, W.-H. Kinetics of Hydrolytic Depolymerization of Melt Poly(ethylene terephthalate). Ind. Eng. Chem. Res. 1998, 37, 1228.

(10) Pusztaszeri, S. F. Method for Recovery of Terephthalic Acid from Polyester Scrap. U.S. Patent 4,355,175, 1982.

(11) Yoshioka, T.; Sato, T.; Okuwaki, A. J . Hydrolysis of Waste PET by Sulfuric Acid at $150{ }^{\circ} \mathrm{C}$ for a Chemical Recycling. Appl . Polym. Sci. 1994, 52, 1353.

(12) Benzaria, J . Process for Production of Alkaline or AlkalineEarth Metal Terephthalate or of Terephthalic Acid, of High Purity, from Polyol Polyterephthalate and in Particular from Waste of an Ethylene Glycol Polyterephthalate. U.S. Patent 5,254,666, 1993.

(13) Schwartz, J . A., J r. Process for Recycling Polyester. U.S. Patent 5,395,858, 1995

(14) Kirby, J . R.; Baldwin, A.J .; Heigner, R. H. Experimental Reactor Thermal-Neutron Activation Analysis Sensitivities. Anal. Chem. 1965, 37, 130.

(15) Namboori, C. G. G.; Haith, M. S. Steric Effects in the Basic Hydrolysis of Poly(ethylene Terephthalate). J . Appl. Polym. Sci. 1968, 12, 1999.

(16) Tindall, G. W.; Perry, R. L. Ester Hydrolysis and Depolymerization of Polyester and Polycarbonate Polymers. U.S. Patent $5,045,122,1991$.

(17) Tindall, G. W.; Perry, R. L.; Spaugh, A. T. Depolymerization of Substantially Amorphous Polyester. U.S. Patent 5,328,982, 1994.

(18) Collins, M. J .; Zeronian, S. H. J . The Molecular Weight Distribution and Oligomers of Sodium Hydroxide Hydrolyzed Poly(ethylene terephthalate). Appl. Polym. Sci. 1992, 45, 797.

(19) Holmes, S. A.; Zeronian, S. H. Surface Area of Aqueous Sodium Hydroxide Hydrolyzed High-Speed Spun Poly(ethylene terephthalate) Fibers. J . Appl. Polym. Sci. 1995, 55, 1573.

(20) Kao, C.-Y.; Cheng, W.-H.; Wan, B.-Z. Investigation of Alkaline Hydrolysis of Polyethylene Terephthalate by Differential Scanning Calorimetry and Thermogravimetric Analysis. J . Appl . Polym. Sci. 1998, 70, 1939.

(21) Kamatani, H.; Konagaya, S.; Nakamura, S. Effect of Phosphoric Acid on the Polycondensation of Bis(2-Hydroxyethyl)terephthalate Catalyzed by Sb(III) Compounds. Polym. J . 1980, $12,125$.

Received for review May 31, 2000

Revised manuscript received October 12, 2000 Accepted October 23, 2000

IE 0005304 